\title{
PALABRAS DE JUAN RAMÓN
}

Al lector asiduo de Juan Ramón Jiménez no le sorprenderá que un poema de su Dios deseado y deseante se llame "En mi tercero mar" (a la manera del "Primero sueño", de sor Juana, o del "Tercero libro de Galatea", de Cervantes) y comience con esas mismas palabras: "En mi tercero mar. .." $(969)^{1}$; ni que otro poema utilice, también en el título y en el texto, la vieja forma compaña, como en el Cantar de mio Cid, en vez de la moderna compañia (1012, 1013); ni que el poeta, trémulo de fe, interpele burlescamente al dudón (996), al descreído Juan Ramón Jiménez de otros tiempos, incapaz de presentir la actual bienaventuranza. Palabras más atrevidas que ésas han salido de su pluma. El poeta ha ido haciéndose y rehaciéndose sin descanso ("Sí, sucederse es mi vida, revivirse") ${ }^{2}$ y haciendo y rehaciendo a su lector. $\mathrm{Y}$ el lector se ha acostumbrado al sucederse, al revivirse de la "Obra", a sus virajes, a sus invenciones continuas y al inquieto vocabulario en que esa transformación ha cristalizado, sobre todo en su última época.

Podremos todavía, después de familiarizados con el éstasis y el trascielo y el "Dios está azul", tropezar con cuerpialma, con dios y con azulazul; pero la lectura repetida y completa nos hará reconocer, bajo las palabras inesperadamente arcaicas o regionales, bajo el coloquialismo o el neologismo travieso, un hilo constante de normalidad: normalidad de alta tensión estética. Si la vigilancia, el empujar contra los límites alcanzados, el complacerse en dar un paso más allá y experimentar con notas y acordes nuevos, se precipitan desde La estación total en un crescendo de estallidos y desgarraduras gramaticales y, en particular, de grandes o pequeños desafíos al léxico español ordinario, no es menos cierto que una aguda conciencia verbal recorría desde el comienzo la obra de Juan Ramón, y se engranaba con su poética de la libertad (es decir, de la fidelidad a sí mismo) y con la preceptiva y crítica sarcásticas de que esa poética solía acompañarse, como de una sombra maligna. En lo hondo, pues, unidad y crecimiento. Frente a los “ánjeles malvas” y los "misticismos de suspiro" de las Primeras poesias (17, 34), no es incon-

1 Los números entre paréntesis indican páginas de la Tercera antolojía poética (1898-1953), Madrid, 1957--Comp. "en este mar tercero" (975).

2 "Márjenes propias y ajenas", en Asom, 10 (1954), núm. 1, p. 10. 
secuencia ni caprichosa ruptura lo que hace brotar formas como el "destino presidente", de "Márjenes propias y ajenas" (p. 9), o como el "solear ['lanzar el sol sus rayos'] empederniente del mediodía" y el "polvo pelucoso de los siglos", de En el otro costado $(878,874)$. Sólo a quien conserve un recuerdo perezosamente esquemático de Platero y yo, o de los versos juveniles de Juan Ramón Jiménez, podrán parecerle estos atrevimientos una tardía contradicción de ideales "clasicistas" (tersura, transparencia, espontaneidad...) afirmados una y otra vez por el poeta. $O$ a quien, con simplismo aún más grave, piense que la obra total de Juan Ramón encarna directa y uniformemente esos anhelos de dulzura e intimidad. Si tenemos presente, en cambio, el lado cruel de su inspiración -escenas como la de "Los gallos" en Platero, toques sombrios en sus Historias, hirientes "Poesías al revés" y "Alejandrinos de cobre" en Esto, paisajes hediondos de perros muertos y almejas podridas $(297,320)-$, y seguimos ese "trazo negro"3 hasta llegar a títulos como "Autorretrato para uso de reptiles de varias categorías", a ciertas esperpénticas pinceladas de Españoles de tres mundos ${ }^{4}$ y al veneno de algunas de sus prosas críticas, y lo enlazamos todo con la constante inquietud expresiva de Juan Ramón Jiménez, traducida en las formas y humores más diversos, entonces podremos, sí, comprobar cómo los neologismos se hacen más abundantes y detonantes en su época última ${ }^{5}$, pero percibiremos a la vez sus afinidades y su entronque en la obra íntegra del poeta.

Inquietud de expresión. El poeta no se consiente la menor pasividad ante el vocabulario recibido. Está siempre pensándolo y repensándolo, bordándolo de variantes, rejuveneciendo o resucitando sus metáforas con una energía que recuerda a veces la de Unamuno, por muy distinta que sea la dirección en que esa fuerza trabaja. Cuando, en vez del usual cangrejo, Juan Ramón escribe cáncer $(877 \mathrm{ss}$.$) , no es que un raro latinismo haya salido del diccio-$ nario para suplantar a su modesto sinónimo. Al escritor no se le

3 "Trazo negro", como se ve, en sentido más amplio que el que dio Rubén Darío, en 1904 , a estas palabras suyas. No me refiero sólo al lirismo fúnebre que, para Rubén, enlazaba la voz del joven poeta de Arias tristes con la de "Ios sonoros, duros y aullantes cantaores" ("La tristeza andaluza", en Tierras solares, Madrid, 1917, p. 77). En la España de Gutiérrez Solana, de Valle-Inclán y de Gómez de la Serna, Juan Ramón Jiménez ocupa también su lugar.

4 Recuérdese que uno de esos mundos es la muerte.

5 Muy útiles datos y observaciones en Concha Zardoya, "El Dios deseado y deseante de Animal de fondo", fns, 12 (1957), núms. 127/28, p. 20, y en Oreste Macrí, "El segundo tiempo de la poesía de Jiménez", LT, 5 (1957), núms. 19/20, pp. 289-295. De esas anotaciones parto, procurando en lo posible completarlas. (Véase ahora, especialmente, "Metafisica e lingua poetica di Juan Ramón Jiménez", del mismo Macrí, en Palatina, Parma, 1958, núm. 5, que he podido consultar sólo después de terminado el presente trabajo). 
ha impuesto cáncer por más libresco y ornamental, sino por más cargado de terribles resonancias. Cuando, en lugar de "hacia el poniente azul y plateado", leemos "hacia el poniente azul y platecido" (928), esta nueva palabra, mientras viene a insertarse armoniosamente en los sueltos asonantes (-i-o) que recorren el poema, subraya a la vez el dinámico carácter verbal de que carecería plateado en ese contexto -adjetivo, como azul, no participio. Un ahinco de invención y retoque personal roe en estos versos y prosas las fronteras del vocabulario académico y las deja como abiertas, vibrantes, en no sé qué extraño desequilibrio creador.

Del mismo modo que Juan Ramón altera las grafías establecidas, e introduce ágiles variaciones en sus rimas y metros ${ }^{6}$, y sutiliza o "aplana" la puntuación, y deforma los moldes sintácticos hasta alcanzar momentos de fuerte atonalidad ${ }^{7}$, así su léxico se complace a menudo en remover, y en subvertir a veces, los hábitos de derivación y composición de palabras (aunque en general utilice afijos ya existentes). Nada más usual que terminaciones como -idad, -or, -ura, -ación, -ancia, -encia, y así Juan Ramón dirá espiralidad (819), amarillor $^{8}$, pardores (87.7), frondor (821) -directamente derivado del sustantivo fronda, como si el poeta quisiera eludir las notas negativas que suelen asociarse a frondosidad-, llenura (875), puesto que plenitud es palabra demasiado lejana del simple adjetivo lleno. Un paso más, y si, en la lengua más o menos común, fragante se corresponde con fragancia, en la de Juan Ramón Jiménez errante da errancia (642). Frente a la pareja color: coloración, de olor resultará "una cortante oloración de éter sulfúrico" (Españoles, p. 138).

6 Unos pocos ejemplos: "Yo no he querido nunca molestaros cantándo- / os..." (Segunda antolojia poética, Madrid, 1952, p. 77); "de sol con hilos de brisa, en- / trecielo puro y salado" (207); "Sí, sí: mas ¿dónde volveré yo a ver la / rosa de luz que se quedó llorando?" (554). Muy frecuentes los pares de versos que, a la vez, forman una unidad superior, un nuevo verso unitario: "Aun entre el mar y el cielo, / por la aurora" (473); cf. "se le enredara, / con el cuerpo, / el alma" (489). Alfonso ReYes, que en su Tertulia de Madrid (Buenos Aires-México, 1950, p. 52) pinta a Juan Ramón como "hombre severo, superior, grave maestro estético", añade a su enumeración este preciso rasgo: "fiero encabritador del verso".

7 Pienso en pasajes como éste: “¿Brentano’s? ¿Scribner’s? „Horrorl No muchos tantos libros. Muchos - ¿dónde? - un libro" (Diario de poeta y mar, Madrid, 1955, p. 116). O como estos otros: "¿Huelva?... ¿Me había dormido? Pero... ¿Las once? ¡Ya! ¡New York otra vez! Duro despertar frío y fuerte. De pie... En el cristal, las gotas, arriba, buscan un surco, lo encuentran y jabajo! Otra, otra... iNew York, maravillosa New York! ¡Presencia tuya, olvido de todo!" (Diario, pp. 86-87); "esta aludida conciencia mejor bella" (1018); "algún terroso verdemente biliado" (Españoles de tres mundos, Buenos Aires, 1958, p. 83); "Disímil así ha de crearse surtidos $\mathrm{H}$ de elementos simpáticos correspondientes; materia, ingrediente, humanos jenerales: caderas de zorra ahumada, lejías de Florida, dulces fósiles", etc. (Españoles, p. 81).

8 Platero y yo, Madrid, 1958 , p. 285. 
Según el modelo de conveniente: conveniencia, conciente (como gusta escribir Juan Ramón): conciencia, sapiente: sapiencia, el retratista de Españoles de tres mundos parte de sonriente y llega sin miedo (p. 145) a frases como: "una fina mirada mate de triste sonriencia".

Pero eso no le basta. Si hay cabrillear, ¿por qué no cabritear (Españoles, p. 137), como sustituyendo una terminación de diminutivo, -illo, por otra, -ito? Fúlgido y refulgente se combinan en un extraño fuljidente (926); plenitud recibe un toque de participio activo y engendra plenitente (1004). Si a dormir corresponde dormitorio, a vivir y morir corresponderán -en uno de esos trechos de zigzag y de lúcido balbuceo que tanto abundan en Españolesvivitorio y mortuorio: "Y no sé por dónde ni en dónde ni cómo, la cámara dormitorio, vivitorio, mortuorio, cámara amarilla, camerino..." (Españoles, p. 139). No importa que el adjetivo mortuorio ya exista, con dos terminaciones, en el idioma. Aquí se ha sustantivado ( $y$ sólo con terminación masculina) por contagio del también existente sustantivo dormitorio y del recién inventado vivitorio. Y la textura sintáctica se complica aún más porque los tres "sustantivos" en -orio vienen a funcionar en este pasaje como adjetivos, todos ellos referidos a cámara (cámara dormitorio, cámara vivitorio, cámara mortuorio, según el modelo de coche comedor, hombre orquesta, etc.) $)^{9}$.

Esta lengua, como electrizada, siempre está pronta a la invención. Toda palabra parece irradiar en ella influjos e incitaciones, repercutir aquí sobre tal otra palabra, conmover o trastornar allí tal otra, provocar más allá el nacimiento de otra nueva. En formas como lo porvenir, el porvenir, la mirada etimologizante de Juan Ramón Jiménez se fija -como la de Unamuno- en los componentes ocultos y en su soldadura y, por lo mismo, descubre un filón de posibles formas parecidas. $\mathrm{Y}$ puesto que lo futuro, lo que está aún por acontecer, por venir, puede precisamente designarse con lo porvenir, el verdadero futuro, el personal, el que experimentamos en enlace unitario y creador con lo ya vivido, será, para el Juan Ramón de En el otro costado $\left(8_{5} 1\right)$, lo porvivir. Hispanoamérica, hispanoamericano: así suele decirse. Pero Juan Ramón se detiene a repensar el proceso histórico que, comprimido, se encierra en la breve fórmula. Desde ese ángulo vuelve a examinar la yuxtaposición de lo hispano y lo americano, y corrige entonces, invirtiendo términos: americoespañol, americohispano, Americohispania ${ }^{10}$. Sabida

9 "Lágrima lucero", en uno de los poemas juveniles de Juan Ramón (31). 10 "Crónica americana", en $U d A$, 31 (1955), pp. 612-615. En la p. 612 aparece también indoespañol americana, en dos palabras, que acaso el autor haya escrito en una sola. En este punto, como en lo que toca a ciertos acentos (niñodiós, niñodios), no siempre es fácil, por ahora, determinar con precisión qué retoques ha introducido la imprenta en los textos de Juan Ramón Jiménez. 
es la profusión con que multiplica en su obra, desde muy temprano, los colores y subcolores, ya aglutinando dos elementos y respetando sin embargo sus terminaciones primitivas: rojoladrillo (444), verdeazul $\left(3^{64}\right)^{11}$, negroazules, verdegrises ${ }^{12}$, ya siguiendo el modelo de verdiseco y verdinegro, de donde rojiseco $(872)$, orinegras ${ }^{13}$, blanquiverde (243) y, en la prosa de los últimos años, agriverde ${ }^{14}$. Alguna vez el poeta, ante las olas amarillas y verdes (995), rompe a hablar al mar mismo y lo invoca con los nombres de verdemar y amarillomar (994). No para pintar el mar, sino el sol, había fundido ya Juan Ramón los dos colores en un solo adjetivo: el "sol verdeamarillo" (319), y hasta en un verbo: desde las hojas de un castaño, "el sol. . verdeamarilla. . . su luz de oro" (397). El clásico verdemar -el de la "verdemar basquiña" de doña Inés en la escena inicial del Caballero de Olmedo- y formas del tipo verdeoscuro, que también Juan Ramón utiliza $(756,774)$, o verdescuro, se reflejan y prolongan en compuestos como verdeluz (48), verdespuma (1022), verdeoro ${ }^{15}$. Pero el verde que no "sale" a apoyarse en otra cosa (mar, oscuridad, espuma, oro), el verde esencial, "hacia adentro", ése nos lo nombrará Juan Ramón con un sorprendente compuesto: verdemismo (868). Si en los versos satíricos de Esto acudía el poeta a juegos de tecnicismos como Neuropatillo y "nuestro Hume-Wundtiano" (201), sistemáticas superposiciones entrarán en su poesía más seria y arrebatada. Lo que en la prosa de "Espacio" (871) es aún rio mio se condensa poco después en riomio $(935)^{16}$. "Ríomar-desierto" (100o) se llama un poema de "Animal de fondo"; pero desde el comienzo mismo nos sale al paso riomar, y en seguida desiertoriomar. En su violenta taquigrafía visional, el poeta salva ritmo y fuerza gracias a estas concentraciones de vocabulario. Necesita ver reinar a su dios tanto en "lo redondo" como en "lo alto": lo colocará en la circumbre (1002). Necesita que la gloria, el "país de países", acoja simultáneamente su cuerpo y su alma: le confiará su cuerpialma (1009).

Porque esta imperiosa expresividad no respeta ni la fisonomía tradicional de las palabras más simples. Ya en un poema de Piedra y cielo (6oo) el crecimiento y repercusión del grito nocturno en el mar se traducía, en un plano, con “. . . más, / más, más, más, más. .." y con “. . vas más allá, vas más allá, vas más allá...”, pero en otro plano nos saltaba a los ojos en una como pintura directa y primaria

$11 \mathrm{Y}$, mucho después, tres veces más -con repique de estribillo, y con tono poético muy alejado del de aquella juvenil Pureza- en un mismo poemita de La estación total (798).

12 Estas dos últimas palabras, en "Isla de la Simpatía (Prólogo muy particular)", Asom, 9 (1953), núm. 1, p. 5 .

13 Segunda antolojia, p. 91.

14 "Isla de la Simpatía...", pp. 6-7.

15 Segunda antolojía, p. 91; Platero, p. 82; "Isla de la Simpatía...", p. 7.

16 Comp. siempremia y miosiempre (948). 
del grito mismo, en tres sucesivos momentos: "Griito en el maar!", "¡Griiito en el maaar!”, "¡Griiiiito en el maaaaar!” Al cielo "azul, azul, azul" de Platero y yo (p. 151) responde el "Mediterráneo azulazulazul" de En el otro costado (868). La 'noche de ébano' se comprime en "noche ébana" (766). España se aparece al desterrado17 como su única "tierra vivida y morida". Morida -contra toda normalidad académica- y no rnuerta, pues ese morir activo, colmo del vivir, nada tiene que ver con lo ya muerto. La simetría de pensamiento ha sometido la frase a una disonante, pero muy gráfica, simetría de forma.

Es la misma voluntariosa conciencia idiomática que ya en $B o$ nanza (317) hacía cantar la salud del poeta como una ruiseñora y que en "Espacio" (870) opondrá al ánjel la "ánjela de la guarda"; que no se contenta con el "aire turquesa" (854) y las "tierras naranjas" (855), y necesita de los "ojos mares" (488), de las "barandas estrellas" (813), de las "lunas soles" (852) y la "fruta seno" (822); que no sólo sustantiva "los jadiós!" (178), los "más allás de oro" (783) y "su dentro" (975), sino "lo solo" (651), "lo todo" (769) y "los ahíes"18; que sacude las barreras convencionales entre nombre propio y nombre común con sus atlánticos y mediterráneos (869), con su abel y su cain (878), con sus ofelias (81) y con la deliberada oposición -aun en una misma página- de Dios y dios (966).

Decir (y bien dicho está) que en la época más reciente de Juan Ramón se dan "como asimiladas y digeridas todas sus otras épocas"19 es subrayar la riqueza de esa poesía última, donde la anterior, las anteriores, perduran y conviven. Lejos, sin embargo, de remansarse en un epílogo blandamente armonioso, la obra tardía de Juan Ramón Jiménez se nos muestra más "frenética de emoción" que nunca. Alcanzada la compleja síntesis, el poeta se lanza a nuevos espacios, y nos asombra con la soltura, el ímpetu de ahondamiento y expansión, la escala amplísima -desde el susurro al grito- de su vuelo final. Las audacias de lenguaje estallan con desusada frecuencia e intensidad en este Juan Ramón maduro y anciano. Una formidable tensión anima su poesía y sus opiniones, y es natural que se refleje cabalmente en su vocabulario. Vemos al poeta concentrado en sus personales búsquedas y nerviosamente atento a las de los otros. Enrostra a Pablo Neruda la falta de un exacto "soplo verbal", de "la palabra representativa y trasmutadora" (Españoles, pp. 125-126); le molesta que Lucila Godoy haya reemplazado su nombre por el exótico "Ga-

17 “De mi Diario poético, 1937-1939 (Fragmentos)", en Universidad de La Habana, mayo-agosto de 1941, p. 24.

18 Españoles, p. 133. Cf. "grabándome con fúljido mi órbita" (975).

19 Tomás Segovia, "Juan Ramón Jiménez ayer y hoy", $L T, 5$ (1957), núms. $19 / 20$, p. 346 . 
briela Mistral" (p. 124); le irrita la vividura de Américo Castro ("Márjenes...", p. 7).

Pero es su propio léxico lo que mejor traduce esa hiperestesia verbal. No sólo en su última época. Quien explorara por dentro las creaciones de vocabulario de Juan Ramón recorrería a la vez la historia de su infatigable hacer poético. Con imágenes como la de la $i s l a$, se ha detenido alguna vez a discurrir sobre el destino de Cuba y de la poesía cubana ${ }^{20}$. La isla y el a-islarse llegarán, en su época de Puerto Rico, a cifra de su empeñoso “jadentro!”, de su anhelo (y predicación) de una espléndida insularidad: no un mero cortar puentes, sino el entrar en contacto con lo esencial y universal, con lo más puro e íntimo. Por añadidura, esa isla espiritualizada ha venido a colmarse también de una agradecida referencia, concretamente geográfica, a la "isla de San Juan de Puerto Rico y de la Simpatía", esa tierra en que vivió Juan Ramón Jiménez sus últimos años y en que él y Zenobia hubieran querido "esperar la resurrección de la carne"'21.

Con internación y reinternación subraya asimismo el poeta el sentido de su viaje alma adentro, en busca de la suprema 'internidad'. Y si la internité de un Valéry replica polémicamente a las variadas fórmulas en que Goethe gustaba condensar - a veces con epigramática exageración- su culto de lo externo, del puro fenómeno, del esplendor con que las cosas del mundo se dan inmediatamente a nuestros ojos $^{22}$, ¡cuán distinta la 'internidad' de Juan Ramón, sobre todo en sus últimos poemas! No, como en el cientificista Valéry, un canto al análisis psicológico, a la trabajosa descomposición metódica del propio pensamiento en ruedecillas y resortes, sino, por una parte, impulso afirmativo, promesa, fe, vislumbre, y por otra, cumplimiento cabal: el pasmo y éxtasis triunfante del hallazgo. $Y$ en el último Juan Ramón, un hallazgo de lo divino unitario que es a la vez yo y tú, yo y la luz, yo y el cielo... "Nada hay dentro, nada hay fuera". Hay un ser único: el Yo radiante en que la internidad se ha hecho eternidad. La jornada queda cumplida. "He llegado a una tierra de llegada", comienza uno de los grandes poemas (998999) de Dios deseado y deseante, y termina: "El todo eterno que es el todo interno". Juego trascendental de sonido y sentido. También aquí, mucho más que un simple retruécano.

Para el lector atento, la fertilidad léxica de Juan Ramón brota "fatalmente" de la misma savia que nutre sus poemas y sus pensa-

20 Prólogo a La poesía cubana, La Habana, 1937, p. xx. Véase también, con los debidos recaudos, el "Coloquio con Juan Ramón Jiménez" de José Lezama Lima, en Analecta del reloj, La Habana, 1953, pp. $43-48$.

21 "Isla de la Simpatía...", p. 13.

22 Maurice Bémol, Variations sur Valéry, Université de la Sarre, 1952, p. 127 . 
res $^{23}$. Ni fuera ni dentro. Palabras, derivación de palabras, formación de nuevas palabras: tampoco para Juan Ramón Jiménez eran unas minucias y accidentes que pudiesen desgajarse de su poesía. En su contexto, eran -son- la poesía misma, exterior e interior a la vez, cuerpo y alma, inescindible cuerpialma.

Harvard University.

Raimundo Lida

23 El rótulo de pensamiento, en su sentido habitual, no abarcaría adecuadamente algunos de sus aforismos y reacciones en prosa. 